\title{
Determinants of hand hygiene compliance in Egypt: building blocks for a communication strategy
}

\author{
A.-L. Lohiniva, ${ }^{1}$ H.Bassim, ${ }^{2}$ S.Hafez, ${ }^{3}$ E.Kamel, ${ }^{2}$ E. Ahmed, ${ }^{3}$ T. Saeed ${ }^{1}$ and M. Talaat ${ }^{1}$
}

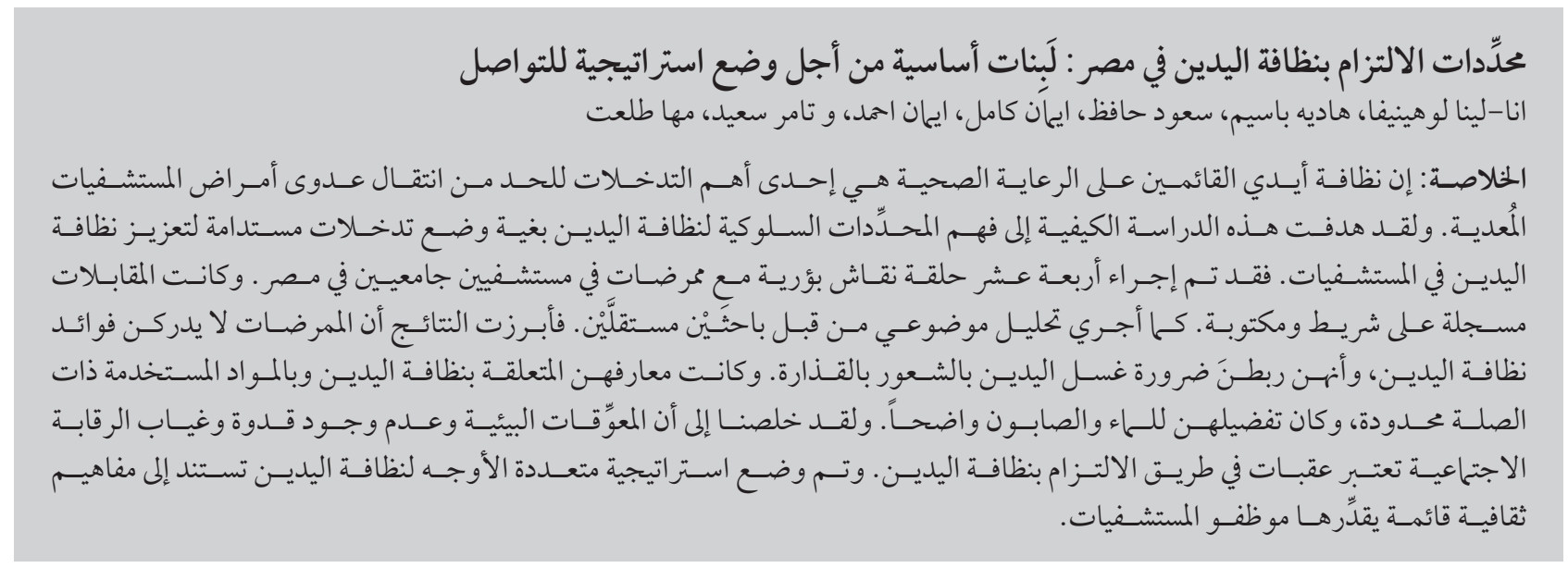

ABSTRACT Hand hygiene of health-care staff is one of the most important interventions in reducing transmission of nosocomial infections. This qualitative study aimed to understand the behavioural determinants of hand hygiene in order to develop sustainable interventions to promote hand hygiene in hospitals. Fourteen focus group discussions were conducted with nurses in 2 university hospitals in Egypt. The interviews were tape recorded and transcribed. Thematic analysis was conducted by 2 independent investigators. The findings highlighted that nurses did not perceive the benefits of hand hygiene, and that they linked the need to wash hands to a sense of dirtiness. Knowledge of hand hygiene and related products was limited and preference for water and soap was obvious. Environmental constraints, lack of role models and social control were identified as barriers for compliance with hand hygiene. A multi-faceted hand hygiene strategy was developed based on existing cultural concepts valued by the hospital staff.

Déterminants du respect de I'hygiène des mains en Égypte : des résultats d'une étude à l'élaboration d'une stratégie de communication

RÉSUMÉ L'hygiène des mains du personnel de santé est l'une des interventions les plus importantes pour réduire la transmission des infections nosocomiales. Une étude qualitative visait à comprendre les déterminants comportementaux de l'hygiène des mains afin d'établir des interventions durables pour la promotion de ce type d'hygiène dans les hôpitaux. Quatorze discussions thématiques en groupes ont été organisées avec le personnel infirmier dans deux hôpitaux universitaires en Égypte. Les entretiens ont été enregistrés puis retranscrits. Une analyse thématique a été menée par deux chercheurs indépendants. Les résultats ont mis en évidence le fait que le personnel infirmier ne percevait pas les avantages de l'hygiène des mains, et qu'il reliait le besoin de se laver les mains à une sensation de saleté. Les connaissances en matière d'hygiène des mains et des produits à utiliser étaient limitées et la préférence pour l'eau et le savon était marquée. Les contraintes environnementales, I'absence de modèles à suivre et de contrôle social ont été identifiés comme des obstacles au respect de l'hygiène des mains. Unestratégie d'hygiène des mains multidimensionelleaétémiseaupointà partirdesconceptsculturels existantsqui étaient importants pour le personnel hospitalier. 


\section{Introduction}

Adherence to proper hand hygiene practices is an effective measure to reduce the risk of health-care associated infections (HCAI) (1-6). HCAIs are a major concern for the safety and quality of health care quality worldwide including Egypt (7-12), as they may lead to prolonged hospital stays, long-term disability, increased resistance of microorganisms to antimicrobials and massive additional financial burden (13).

Several programmes have been developed to increase hand hygiene practices in health-care facilities, but only a few of them have demonstrated long-lasting changes in compliance. Adherence to hand hygiene guidelines remains suboptimal in many facilities. Although understanding of the determinants of hand hygiene behaviours is improving, there is still an urgent need to assess the longer and short-term success of strategies used in hand hygiene promotion (14-24). Recently, studies have looked at the social and behavioural contexts affecting hand hygiene practices. However, much still needs to be learned (25-32). There are no previous studies on hand hygiene determinants in the Egyptian health-care setting.

Ain Shams University hospital in Cairo and Alexandria University hospital in Alexandria were interested in increasing hand hygiene compliance among nurses and promoting the use of alcohol gel between patient contacts, in line with World Health Organization guidelines (13). The Infection Control Unit of the US Naval Medical Research Unit No. 3, in collaboration with the 2 university hospitals, designed and implemented a pilot hand hygiene campaign. In order to develop the campaign, there was a need to explore factors associated with non-compliance with hand hygiene guidelines specifically in the Egyptian context. Qualitative methods were considered suitable for studying hand hygiene adherence because they provide a better understanding of the broader environment where hand hygiene takes place and for explaining the reasons and meanings for the hand hygiene behaviours. The findings of this study were used to develop communication strategies to promote hand hygiene in Egyptian health-care facilities.

\section{Methods}

\section{Design}

The study and the campaign were conducted in adult intensive care units, neonatal intensive care units and surgical wards of Alexandria and Ain Shams University hospitals. Departments were selected by the infection control teams as the pilots for the campaign as health-care workers from these wards had been involved in previous hand hygiene campaigns and therefore had a basic knowledge of hand hygiene. Data were collected through focus group discussions (FGD) to elicit nurses' descriptions related to determinants of hand hygiene.

\section{Recruitment and sample}

The study included 14 FGD with a total of 96 nurses. The participants were either graduates from the High Institute of Nursing (4 years education) or school-based nurses ( 2 years vocational education at the nursing school). The work experience of the participants varied from 2 to 25 years and only 5 were males. Of the FGD 8 were conducted at Ain Shams University (3 with graduate nurses and 5 with vocationally trained nurses) and 6 at University of Alexandria ( 1 with graduate nurses and 5 with vocationally trained nurses).

The participants were chosen for the study based on their interest and availability to discuss hand hygiene with the members of the research team. Study investigators, together with the department heads and infection control teams, solicited volunteers by visiting each ward and explaining the study objectives to the nurses. If the individual was interested in joining the focus group, the study investigator invited her/him for the discussion the following day.

\section{Focus group discussions}

The FGD took 30-60 minutes each. All discussions were led by a moderator and supported by an assistant who took notes. In addition, all FGD were tape recorded. The moderator used a focus group guide consisting of open-ended questions to cover all the topics of interest. At the start of each discussion, it was emphasized that participation in the discussion was voluntary. The participants were also encouraged to discuss their opinions freely. All FGD started with verbal informed consent and all of them were conducted in a private room to maintain confidentiality. The discussion guide included several topics such as reasons for (non) compliance with hand hygiene measures, advantages and disadvantages of hand hygiene measures and indications and impact of hand washing with soap and water versus alcohol hand rub.

\section{Analysis}

As all the FGD were tape recorded, the analysis began by translating and transcribing the tapes from Arabic into English. For quality control, a bilingual member of the research team reviewed a random section of all transcripts and compared them with the original audio recordings to ensure accuracy (33). Data analysis of the transcribed text was conducted using thematic analysis that aimed to identify emerging themes for determinants of hand hygiene as described by Patton (34). The major goal in analysing the data was to identify common themes and variation of themes across the groups that captured determinants for hand hygiene behaviours. The analyst identified coded passages and key terms from the text that were collapsed into themes and sub-themes. The analysis also assessed 
any variation of themes across different groups.

\section{Ethical considerations and approvals}

The study was reviewed and approved by the institutional review board of the Naval Medical Research Unit No. 3 in compliance with all applicable federal regulations governing protection of human subjects. All participants provided verbal informed consent in Egyptian Arabic. Personal identifying information was not collected from study participants and if names or other identifying information were mentioned during the FGD they were deleted from the transcripts.

\section{Results}

The analysis produced 4 themes and 10 sub-themes reflecting factors that influence hand hygiene behaviour. In general, the themes were consistent across various groups of respondents; differences, if present, between the university hospitals or types of nurses were noted.

All the FGDs concluded that a hand hygiene policy existed in their hospital, but health-care workers frequently did not comply with the policy.

\section{Theme 1: Attitudes \& beliefs related hand hygiene measures}

Sub-theme: Importance of hand hygiene measures

The majority of respondents did not consider hand hygiene practices important. In most of the discussions, respondents did not believe that hand hygiene could prevent cross-infection. The only exception were nurses from the neonatal care units of both universities, who believed that hand hygiene practices helped save lives in the intensive care units and that the practices were especially important when dealing with 1 -month-old infants. Most respondents did not believe that hand hygiene was effective in protecting health-care workers from infections either. In several FGD, respondents mentioned the importance of using gloves, masks and gowns as a measure to protect them and the patients. In addition, respondents in several discussions mentioned their concern about catching airborne infections or blood-borne pathogens due to needle-stick injuries, but believed that hand hygiene had little effect on protecting them against those infections. It was not possible to detect clear differences between the perceptions of graduate nurses and vocationally trained nurses or between the 2 universities.

\section{Sub-theme: Sense of having clean hands}

Respondents in all FGD reported washing hands whenever they had visible dirt or their hands were sticky. They also reported wanting to wash hands especially after touching blood, stool or urine. Furthermore, in several FGD, respondents explained that they were interested in washing hands whenever they got an uncomfortable feeling, e.g., after contact with unclean patients who either had open wounds or smelled bad. A couple of focus groups also mentioned that unfriendly, bad-mannered patients or those who exhibited abnormal behaviour led to a sense of uncleanliness and the need to wash hands. Several FGD also concluded that the uncomfortable feeling and the need to clean their hands was also related to perceptions of being in unclean, smelly, disorganized, crowded surroundings or outside of ordinary workplaces.

The great majority of respondents clearly preferred using soap and water instead of alcohol rub because the idea of running water and rubbing hands together provided them with a sense of cleanliness that could only be accomplished by using soap and water.

\section{Sub-theme: Importance of gloving}

Many respondents believed that hand hygiene between touching patients was not a necessity when they wore gloves because they did not get their hands dirty. However, they did acknowledge that hand hygiene with soap and water or with alcohol was important if their gloves were somehow penetrated.

\section{Theme 2: Knowledge of hand hygiene}

The majority of respondents seemed to be confused about the choice and effect of the different hand hygiene products. Many school-based nurses were also not sure about the effect of different hand hygiene products. For example, many did not think alcohol rub between touching patients was essential if hands had no visible dirt and insisted that washing hands using water and soap would be the best option. Some of the nurses believed that alcohol rub could only be used as an additional precaution if a patient was particularly infectious. Overall, there was much confusion related to the effects of soap and alcohol.

\section{Theme 3: Environmental constraints}

\section{Sub-theme: Lack of supplies and fa-} cilities

A majority of the nurses in both hospitals referred to the lack of hand hygiene due to a shortage of products (soap or alcohol) and sinks as the main constraint to complying with hand hygiene guidelines. The problem varied from one department to another. Some departments had no sinks and health-care workers were expected to walk to the next department or to their locker to wash their hands. Other departments had several sinks and one ward had a sink beside each bed. In some departments there was a periodic lack of supplies and in other departments the problem was continuous.

In some FGD, respondents explained that supplies existed but accessing them was difficult. The reasons for difficult access included lack of organization as the person responsible for the storage was not always available and/or 
alcohol gel bottles were located at the far end of the ward.

\section{Sub-theme: Lack of time}

Many respondents mentioned that a heavy workload prevented them from following hand hygiene policies especially in the evening and night shifts. Others stated that the workload was always high and therefore it always impacted hand hygiene practices.

\section{Sub-theme: Side-effects of hand hy-} giene products

Most of the respondents stated that the reason for not using alcohol rub or washing hands regularly was because it made their hands dry and occasionally caused an allergic reaction or even sores. A couple of nurses also noted that if hands had wounds, which often was the case, the use of alcohol rub was painful.

\section{Theme 4: Social and cultural norms}

\section{Sub-theme: Lack of role models}

In several discussions, respondents pointed out that physicians themselves often did not comply with hand hygiene policies and did not give nurses the opportunity to perform hand hygiene. Both institute-based and school-based nurses in Cairo and Alexandria mentioned that it would be difficult and embarrassing to ask for permission to wash their hands in the middle of work. As long as hand washing was not enforced by doctors and there was no visible dirt on their hands, nurses were unlikely to comply with hand hygiene guidelines. One group of school-based respondents explained that they sometimes continued their work with blood on their hands following the example of physicians.

\section{Sub-theme: Lack of social control}

In most of the FGDs, respondents explained that no one was monitoring the implementation of hand hygiene policy in the hospital. The only exception was from the neonatal care unit where doctors closely followed up on the hand hygiene compliance of nurses. They also reminded nurses constantly of hand hygiene, if necessary.

\section{Sub-theme: Adapted social norm}

In one of the hospitals, discussions demonstrated that the policy to undertake hand hygiene between touching patients had been adapted to better fit the realities of the hospitals. The new behaviour norm that had come to be accepted was to perform hand hygiene measures before the start of a procedure such as giving medication to all patients of the ward. The norm had become so well established that respondents believed that it was in accordance with the hospital policy that in fact required hand hygiene between touching patients.

\section{Discussion}

This study provided valuable in-depth information about determinants that influence hand hygiene behaviours in select university hospitals in Egypt. The information provided was used in developing a communication strategy to increase compliance with hand hygiene practices.

Respondents did not perceive the benefits of hand hygiene practices between touching patients. The finding is of crucial importance, staff are unlikely to change their hygiene behaviours if they do not perceive the benefits (30). The findings of this study differed slightly from studies conducted in the Netherlands and Canada, which showed that health-care workers believed hand hygiene practices protected against cross-infection and were a means of self-protection for health-care workers $(26,29)$. The need to communicate the effectiveness of hand hygiene as an important aspect of standard infection prevention was considered in our communication strategy. Education about the chain of transmission of infectious diseases in the health-care setting, modes of infection and the scientific evidence on the effectiveness of hand hygiene in reducing hospital acquired infections was emphasized.

This study, consistent with several other recent studies, showed how nurses make their own assessments about the degree of dirtiness of patients or surroundings. Based on this assessment they determined whether to wash their hands, rather than followed the hospital's guidelines for hand hygiene $(26,30)$. Also, the study provided an indication that the motivation for performing hand hygiene was influenced more by the desire to feel clean rather than to protect patients, as previously suggested by other studies $(30,35)$. Knowing that cultural concepts and images can be used to modify current behaviours rather than trying to work against them, our strategic communication plan focused on promoting the existing key motivators for hand hygiene, namely cleanliness and the desire to be clean.

Misconceptions regarding the protective nature of gloves was evident and this has been identified in several studies as an obstacle to improved hand hygiene. Failure to change or remove contaminated gloves was a major component in poor compliance with hand hygiene and carried a high-risk of microbial transmission $(36,37)$. Therefore, it was considered important that the messages of the hand hygiene campaign also emphasized indications for gloving and associated hand hygiene.

The findings of our study showed that providing information about hand hygiene products is required. Currently, understanding among respondents was inconsistent regarding the use of soap and water and/or alcohol gel. Both the indications and effect of hand hygiene practices and products was unclear to respondents. These findings are in line with previous studies that also highlighted the importance of knowledge to improve adherence to hand hygiene guidelines (29). 
The study also identified important environmental constraints that required attention by the hospital management. Logistical problems, related to the availability and accessibility of critical supplies, varied between wards but remained an important obstacle for better compliance with hand hygiene practices. Lack of hand hygiene supplies and time is a common complaint of health-care workers around the world (26). Our communication strategy included the development of an enabling environment that included plans to ensure the availability of critical supplies.

Reported disadvantages of hand hygiene products such as dryness and allergic reactions require careful investigation and product testing to find the most suitable hygiene products. Hospital infrastructure and lack of sinks should be taken into consideration when developing ward-based hand hygiene policies.

Lack of time to wash hands would require adjusting workforce schedules; however, due to lack of medical staff and especially nursing staff in Egypt, it is not likely that hospital management is able to lessen the workload of the nurses in the near future. The communication strategy included messages to promote the use of alcohol rub by emphasizing a change of system and behaviour from time-consuming hand washing with soap and water.

The findings also showed that social and cultural dimensions impacted hand hygiene behaviours. The lack of role models and non-existent social norms were identified as important determinants of non-compliance with hand hygiene practices, which is not surprising in such an authoritarian culture where lower level employees are accustomed to follow orders from the higher level employees without much thought. Government employees are not requested to evaluate situations or options, therefore they may find it challenging to make decisions or modify behaviours without orders and follow up from their superiors. Based on these cultural considerations, the communication strategy included institutionalizing a performance feedback system that has been proven effective in changing and sustaining hygiene behaviours elsewhere (22). The performance feedback system included regular observations of nurses' hand hygiene practices and direct feedback provided by supervisors. The strategy also outlined an integrated approach for promoting hand hygiene by including all health-care staff, such as doctors and others in positions of authority who are respected role models for others. The strategy also promoted hand hygiene by linking it to quality of care that reflects respect and dignity as these values are appreciated in the Egyptian culture.

Increased tolerance towards working with dirty hands is a challenge, and modified policies that better fit the realities of the health-care facilities needs to be tackled. Developing new social norms is a long term process, and requires long term commitment from the policy-makers, as was concluded also in a study conducted in Indonesia (27).

\section{Conclusions}

The study demonstrated that social and behavioural analysis of hand hygiene can contribute to an accurate understanding of hand hygiene practices. The findings also moved away from the simplistic idea that improving knowledge about germs and diseases will change behaviour. Integrating the findings of the studies into a targeted communication plan will likely have a direct impact on changing behaviours to promote improved hand hygiene in Egypt.

\section{Acknowledgements}

The authors are grateful to the many staff members of Cairo and Alexandria University hospitals who participated in these focus groups, and to the department managers and other hospital staff who supported the study by assisting in recruitment of the study participants.

Funding: The study was supported by USAID work unit no. 80000.000.000. E0022. The authors are contractors supported by military funding at the US Naval Medical Research Unit No. 3. This work was prepared as part of their official duties. Title 17 U.S.C. $\$ 105$ provides that "Copyright protection under this title is not available for any work of the United States Government". Title 17 U.S.C. $\$ 101$ defines a US Government work as a work prepared by a military service member or employee of the US Government as part of that person's official duties.

The views expressed in this article are those of the authors and do not necessarily reflect the official policy or position of the United States Navy, United States Department of Defense, the United States Government or the Egyptian Ministry of Health.

Competing interests: None declared.

\section{References}

1. Pittet D. Clean hands reduce the burden of disease. Lancet. 2005 Jul 16-22;366(9481):185-7. PMID:16023493

2. Capretti MG, Sandri F, Tridapalli E, Galletti S, Petracci E, Faldella G. Impact of a standardized hand hygiene program on the incidence of nosocomial infection in very low birth weight infants. Am J Infect Control. 2008 Aug;36(6):430-5. PMID:18675149

3. Nguyen KV, Nguyen PTM, Jones SL. Effectiveness of an alcohol-based hand hygiene programme in reducing nosocomial infections in the Urology Ward of Binh Dan Hospital, 
Vietnam. Trop Med Int Health. 2008 Oct;13(10):1297-302. PMID:18937745

4. Allegranzi B, Pittet D. Role of hand hygiene in healthcare-associated infection prevention. J Hosp Infect. 2009 Dec;73(4):30515. PMID:19720430

5. Erasmus V, Daha TJ, Brug H, Richardus JH, Behrendt MD, Vos $M C$, et al. Systematic review of studies on compliance with hand hygiene guidelines in hospital care. Infect Control Hosp Epidemiol. 2010 Mar;31(3):283-94. PMID:20088678

6. Cipolla D, Giuffrè M, Mammina C, Corsello G. Prevention of nosocomial infections and surveillance of emerging resistances in NICU. J Matern Fetal Neonatal Med. 2011 Oct;24 Suppl 1:23-6. PMID:21942585

7. Calfee DP. Crisis in hospital-acquired, healthcare-associated infections. Annu Rev Med. 2012;63:359-71. PMID:22017445

8. Bagheri Nejad S, Allegranzi B, Syed SB, Ellis B, Pittet D. Healthcare-associated infection in Africa: a systematic review. Bull World Health Organ. 2011 Oct 1;89(10):757-65. PMID:22084514

9. Gupta A, Kapil A, Lodha R, Kabra SK, Sood S, Dhawan B, et al. Burden of healthcare-associated infections in a paediatric intensive care unit of a developing country: a single centre experience using active surveillance. J Hosp Infect. 2011 Aug;78(4):323-6. PMID:21676495

10. Saied T, Elkholy A, Hafez SF, Basim H, Wasfy MO, El-Shoubary $\mathrm{W}$, et al. Antimicrobial resistance in pathogens causing nosocomial bloodstream infections in university hospitals in Egypt. Am J Infect Control. 2011 Nov;39(9):e61-5. PMID:21835504

11. Hafez S, Saied T, Hasan E, Elnawasany M, Ahmad E, Lloyd L, et al. Incidence and modifiable risk factors of surveillance of surgical site infections in Egypt: a prospective study. Am J Infect Control. 2012 Jun;40(5):426-30. PMID:21943830

12. Talaat M, Hafez S, Saied T, Elfeky R, El-Shoubary W, Pimentel G. Surveillance of catheter-associated urinary tract infection in 4 intensive care units at Alexandria university hospitals in Egypt. Am J Infect Control. 2010 Apr;38(3):222-8. PMID:19837480

13. Guidelines on hand hygiene in health care. First global patient safety challenge. Clean care is safer care. Geneva: World Health Organization; 2009.

14. Mertz D, Dafoe N, Walter SD, Brazil K, Loeb M. Effect of a multifaceted intervention on adherence to hand hygiene among healthcare workers: a cluster-randomized trial. Infect Control Hosp Epidemiol. 2010 Nov;31(11):1170-6. PMID:20923288

15. Chen YC, Sheng WH, Wang JT, Chang SC, Lin HC, Tien KL, et al. Effectiveness and limitations of hand hygiene promotion on decreasing healthcare-associated infections. PLoS One. 2011;6(11):e27163. PMID:22110610

16. Trick WE, Vernon MO, Welbel SF, Demarais P, Hayden MK, Weinstein RA; Chicago Antimicrobial Resistance Project. Multicenter intervention program to increase adherence to hand hygiene recommendations and glove use and to reduce the incidence of antimicrobial resistance. Infect Control Hosp Epidemiol. 2007 Jan;28(1):42-9. PMID:17230386

17. Pittet D, Simon A, Hugonnet S, Pessoa-Silva CL, Sauvan $\mathrm{V}$, Perneger TV. Hand hygiene among physicians: performance, beliefs, and perceptions. Ann Intern Med. 2004 Jul 6;141(1):1-8. PMID:15238364

18. Swoboda SM, Earsing K, Strauss K, Lane S, Lipsett PA. Electronic monitoring and voice prompts improve hand hygiene and decrease nosocomial infections in an intermediate care unit. Crit Care Med. 2004 Feb;32(2):358-63. PMID:14758148

19. Won SP, Chou HC, Hsieh WS, Chen CY, Huang SM, Tsou KI, et al. Handwashing program for the prevention of nosocomial infections in a neonatal intensive care unit. Infect Control Hosp Epidemiol. 2004 Sep;25(9):742-6. PMID:15484798

20. Pittet D, Hugonnet S, Harbarth S, Mourouga P, Sauvan V, Touveneau $\mathrm{S}$, et al. Effectiveness of a hospital-wide programme to improve compliance with hand hygiene. Infection Control Programme. Lancet. 2000 Oct 14;356(9238):1307-12. PMID:11073019
21. di Martino P, Ban KM, Bartoloni A, Fowler KE, Saint S, Mannelli $F$. Assessing the sustainability of hand hygiene adherence prior to patient contact in the emergency department: A 1-year postintervention evaluation. Am J Infect Control. 2011 Feb;39(1):14-8. PMID:20965610

22. Mayer J, Mooney B, Gundlapalli A, Harbarth S, Stoddard GJ, Rubin MA, et al. Dissemination and sustainability of a hospitalwide hand hygiene program emphasizing positive reinforcement. Infect Control Hosp Epidemiol. 2011 Jan;32(1):59-66. PMID:21128786

23. Forrester LA, Bryce EA, Mediaa AK. Clean Hands for Life: results of a large, multicentre, multifaceted, social marketing hand-hygiene campaign. J Hosp Infect. 2010 Mar;74(3):225-31. PMID:20153550

24. Gould DJ, Moralejo D, Drey N, Chudleigh JH. Interventions to improve hand hygiene compliance in patient care. Cochrane Database Syst Rev. 2010;8(9):CD005186. PMID:20824842

25. Hautemaniere A, Cunat L, Diguio N, Vernier N, Schall C, Daval $\mathrm{MC}$, et al. Factors determining poor practice in alcoholic gel hand rub technique in hospital workers. J Infect Public Health. 2010;3(1):25-34. PMID:20701888

26. Erasmus V, Brouwer W, van Beeck EF, Oenema A, Daha TJ, Richardus JH, et al. A qualitative exploration of reasons for poor hand hygiene among hospital workers: lack of positive role models and of convincing evidence that hand hygiene prevents cross-infection. Infect Control Hosp Epidemiol. 2009 May;30(5):415-9. PMID:19344264

27. Marjadi B, McLaws ML. Hand hygiene in rural Indonesian healthcare workers: barriers beyond sinks, hand rubs and in-service training. J Hosp Infect. 2010 Nov;76(3):256-60. PMID:20850197

28. 28. Sahay S, Panja S, Ray S, Rao BK. Diurnal variation in hand hygiene compliance in a tertiary level multidisciplinary intensive care unit. Am J Infect Control. 2010 Sep;38(7):535-9. PMID:20579772

29. Jang JH, Wu S, Kirzner D, Moore C, Youssef G, Tong A, et al. Focus group study of hand hygiene practice among healthcare workers in a teaching hospital in Toronto, Canada. Infect Control Hosp Epidemiol. 2010 Feb;31(2):144-50. PMID:20017635

30. Whitby M, McLaws ML, Ross MW. Why healthcare workers don't wash their hands: a behavioral explanation. Infect Control Hosp Epidemiol. 2006 May;27(5):484-92. PMID:16671030

31. MacDonald A, Dinah F, MacKenzie D, Wilson A. Performance feedback of hand hygiene, using alcohol gel as the skin decontaminant, reduces the number of inpatients newly affected by MRSA and antibiotic costs. J Hosp Infect. 2004 Jan;56(1):56-63. PMID:14706272

32. Whitby M, Pessoa-Silva CL, McLaws ML, Allegranzi B, Sax H, Larson E, et al. Behavioural considerations for hand hygiene practices: the basic building blocks. J Hosp Infect. 2007 Jan;65(1):1-8. PMID:17145101

33. Boyatzis RE. Transforming qualitative information: Thematic analysis and code development. Thousand Oaks (California): Sage Publications; 1998.bok

34. Patton MQ. Qualitative research and evaluation methods. 3rd ed. Thousand Oaks (CA): Sage Publications; 2002.bok

35. Curtis VA, Danquah LO, Aunger RV. Planned, motivated and habitual hygiene behaviour: an eleven country review. Health Educ Res. 2009 Aug;24(4):655-73. PMID:19286894

36. Fuller C, Savage J, Besser S, Hayward A, Cookson B, Cooper B, et al. "The dirty hand in the latex glove": a study of hand hygiene compliance when gloves are worn. Infect Control Hosp Epidemiol. 2011 Dec;32(12):1194-9. PMID:22080658

37. Girou E, Chai SH, Oppein F, Legrand P, Ducellier D, Cizeau F, et al. Misuse of gloves: the foundation for poor compliance with hand hygiene and potential for microbial transmission? Hosp Infect. 2004 Jun;57(2):162-9. PMID:15183248 